\title{
Investigating the Relationship between Students' Personality Traits in Single-Child, Two-Child and Multiple-Child Families with Parent-Child Relationship
}

Iranian Evolutionary and Educational Psychology Journal March 2020: 24-32 (C) University of Hormozgan Publication 2020 DOI: http://ieepj.hormozgan.ac.ir

\section{Ziba Sherafati', Amir Hoshang Mehryar ${ }^{2 *}$, Mohammad Khayyer ${ }^{3}$, Hojatollah Javidi ${ }^{4}$}

\begin{abstract}
The purpose of this study was to investigate the relationship between personality characteristics of single-parent, two-parent and multi-parent families with their parent-child relationship in Sari. In a correlational study, 324 high school male and female high school students in Sari were selected by simple random sampling and completed the NEO 5-Factor Personality Questionnaire and Parent-Child Relationship Questionnaire (PCRS). The data was analyzed by SPSS software using descriptive statistics and linear regression. The results showed that personality traits explained $49.5 \%$ variance of father-child relationship in single-parent families, $25.4 \%$ variance of father -child relationship in two-child families and $26.3 \%$ variance of father -child relationship in multi-child families $(\mathrm{p}<0.01)$. Furthermore, the results indicated that personality traits explained $20.8 \%$ variance of mother-child relationship in single-parent families, 36.9\% variance of mother-child relationship in two-child families and $32.7 \%$ variance of mother-child relationship in multi-child families $(\mathrm{p}<0.01)$. Therefore, personality traits of students are effective in explaining the parent-child relationship of families.
\end{abstract}

Keywords: Personality traits, parent-child relationship, single-child, two-child, multiple-child, students.

\section{Introduction}

One of the fundamental topics of psychology is the personality traits that underlie the behavioral system of individuals. Addressing this issue will highlight specific aspects of people's performance in different contexts. Personality has been examined from various perspectives, but Allport has presented the most fully definition of personality: "Personality is a dynamic organization of the mental and physical systems within the individual and the characteristics of the individual which determines his behavior and thinking(Cervone \& Pervin, 2015; Pervin, 1970). Individuals 'personality traits affect their performance in the family, and the family itself, in turn, affects individuals' personality traits. Of all the institutions, organizations, and social institutions, the family has a special role and importance. No society can claim health if it does not have a healthy family. They are also not immune from social harm if they are unaware of the impact of the family(Fadaei, Kanani, Molavi,

1. PhD Student, Department of Psychology, Marvdasht Branch, Islamic Azad University, Marvdasht, Iran

2. Professor, Department of Psychology, Marvdasht Branch, Islamic Azad University, Marvdasht, Iran

*Corresponding author email: Ahmehryar2003@yahoo.com

3. Professor, Department of Psychology, Marvdasht Branch, Islamic Azad University, Marvdasht, Iran

4. Associate Professor, Department of Psychology, Marvdasht Branch, Islamic Azad University, Marvdasht, Iran 
\& Nouri, 2009). Personality traits affect the performance of individuals in all areas of life; it is a distinctive trait, attribute, or quality. In everyday life, we often follow the trait approach when describing the personality of a person we know. We tend to select prominent features or factors and use them to summarize what a person looks like. Grouping people by attributes is easy and appealing to common sense and it may be explained that the trait and personality approach has been around for many years. Hippocrates distinguished four types of people: happy, sad, anxious, and nervous. The causes of these different types were intrinsic fluids or temperaments(Allen, 2015; Schultz \& Schultz, 2016). On the other hand, Costa Jr and McCrae (2008), followed big five factors in personality structure based on what was previously designed by experts and researchers such as Norman (1963): Neuroticism, extraversion (introversion), openness, agreeableness and Conscientiousness. Neuroticism is the tendency to experience negative emotions, such as anger, anxiety, or depression. It is sometimes called emotional instability, or is reversed and referred to as emotional stability. This dimension also includes sensitivity to unrealistic beliefs, poor control of one's desires, and ineffective strategies for coping with stress. Extraversion is regarded as by breadth of activities (as opposed to depth), assurgency from external activity/situations, and energy creation from external means. The trait is marked by definite engagement with the external world. Extraverts enjoy interacting with people, and are often perceived as full of energy. They tend to be enthusiastic, action-oriented individuals. They possess high group visibility, like to talk, and assert themselves. Extraversion involves socialization and traits such as vitality, strength, assertiveness, need for activity, excitement and stimulation. Openness is a general obligation for art, emotion, exploration, uncommon ideas, imagination, curiosity, and variety of experience. People who are open to experience are intellectually curious, open to emotion, sensitive to prettiness and willing to try new things. They tend to be, when compared to closed people, more creative and more aware of their feelings. The agreeableness trait reflects individual differences in general concern for social harmony. Agreeable individuals value getting along with others. They are generally considerate, sympathetic, substantial, trusting and responsible, helpful, and willing to share their interests with others. Finally, Conscientiousness is a predisposition to display self-discipline, act loyally, and strive for achievement against measures or outside expectations. It is related to the way in which people control, regulate, and direct their impulses. High conscientiousness is often considered as being persistent and focused. Low conscientiousness is associated with flexibility and spontaneity, but can also appear as slovenliness and lack of consistency(Avia et al., 1995; Helle, Trull, Widiger, \& Mullins-Sweatt, 2017).

Family size is one of the determinants of children's personality traits(Morss, 1990; Schaffer, 2006). Family size is decreasing worldwide, especially in developed countries. In India, family size has declined over the past two decades. An examination of the human condition of India shows that the percentage of single-child families has increased(Basu \& Desai, 2010). While the growth of "single children" and "children with one sibling" are all going through the same stages of development, it creates a different family environment. Single children grow up in a nucleus of a family of two adults. Parents and siblings are the main contributors to children's personality development. Therefore, "single children" will never achieve such conditions as playing with siblings, helping each other, providing emotional support or engaging with siblings. Sisters and brothers are the first intimate friend, protector, guide, competitor, as well as an enemy. In personality development, "single children" are deprived of many pleasant and unpleasant experiences of having siblings. Thus, it is commonly believed that "single children" are devastated, selfish and alone, alienated from society, less cooperative, less dependent, but more intelligent than children who have siblings(Stronge, Shaver, Bulbulia, \& 
Sibley, 2019).

Riggio (1999), examined personality dimensions such as extraversion-introversion and neuroticism - stability in children with and without siblings. The results of his study showed that there is only a marginal difference between those with and without siblings in neuroticism. Chan-Ob, Boonyanaruthee, Pinyopornpanich, Intaprasert, and Kuntawongse (2002), concluded that "single children" are more ambitious, have broader interests, are more comprehensive, and more confident, intellectual, smarter, and more independent than first and middle children in several children families. Liu, Munakata, and Onuoha (2005), examined the mental health of single and multiple children in urban and rural areas of China. The results showed that single children in urban areas have poor mental health. Also, single children in urban areas scored higher in neuroticism, depression, interpersonal dependency, and anxiety. This means that the "single children" were significantly more neurotic. Goel and Aggarwal (2012), found that children with siblings were more confident than single children. In terms of personality, there is a difference between single children and children with siblings(Philip, 2015). However, Ha and Tam (2011), found that "single children" in personality traits were relatively similar to those of siblings. Polit and Falbo (1987), also reported there was no significant difference in personality (with respect to intra-gender comparisons) between single boys and boys with one sibling, single girls, and girls with one sibling.

On the other hand, communication is very important in social relationships and is a necessity for all relationships and plays a vital role when it comes to parent-child interaction. Creation and maintaining the relationships between parents and children caused in strong interaction between parents and children and significantly contributes to mutual understanding and acceptance between parents and children(Popov \& Ilesanmi, 2015). Carnes-Holt (2012), argues that parent-child interaction is the first indicator of child communication and an important and vital relationship for security and love is consisted of a combination of behaviors, feelings, and expectations that are unique to a particular parent and a particular child. Most of researchers have also found that family factors, and especially parenting behaviors during childhood, play an important role in the development of behavioral problems in childhood and adulthood(Shakerinia \& Asghari, 2016). Research on behavioral problems has often found that behavioral disorders such as aggression are more likely to be caused by troubled families, unhealthy structure, and poor parent-child relationships rather than genetic and biological factors(Yaacob \& Siew, 2010). Werneck, Eder, Yanagida, and Rollett (2014), also analyzed the long-term impact of their parent-adolescent relationships on 175 Austrian families with data measured in three stages over an 18-year period.

In the last few years, couples have preferred to keep their families smaller and many of them even prefer to have only one child. The results showed that there was no significant difference between single children and children with one sibling in the five personality factors (openness to experience, conscientiousness, extraversion, agreeableness, and neuroticism). Philip (2015), in a study entitled 'Personality Development and Parental Support: A Comparative Analysis of Single Children and Siblings in Bangalore', quoted by Goel and Aggarwal (2012), indicated single children were more confident compare to children with siblings. But Philip (2015), found there was a significant difference in personality between single children and children with siblings. On the other hand, Jaafari (2017), in his thesis entitled "Comparing the personality profile of adolescents in single children and multiple children families" concluded there was no significant difference between personality profile (five major personality factors) of adolescents in single children and multiple 
children families.

Also, in a study, Heratian, Satourian, Zarei, Janbuzargi, and Agaharis (2015), concluded that there was a significant difference between the two groups (parents with one child and parents with multiple children) in marital conflict variables, irrational beliefs, early incompatible schema and religious beliefs. Individuals with more religious affiliation, and fewer early incompatible schema and irrational beliefs, are more likely to have more children. In addition, parents with multiple children have less marital conflict experience than single parents. As mentioned above, very few researches in Iran and outside of Iran have investigated the relationship between personality characteristics of students in single-child, two-child and multi-child families with their parent-child relationship. Therefore, in the present study, we were going to study the relationship between personality characteristics of these students with their parent-child relationship.

\section{Material and Method}

The present study was a descriptive and correlational study. The statistical population of the study consisted of all male and female students of first, second and third grade high schools of public and private schools in Sari city, Iran in the academic year of 2019 with a total of 16,898 students. The sample size was estimated at 370 based on Morgan's table. Purposeful sampling was used to select the sample; students were selected based on single-child, two-child and multiple-child families. Then, based on single-child, two-child, and multiple-child families, the tests were performed on 500 subjects, but 324 questionnaires were completed correctly. Questionnaires were administered both individually and in groups over a three-month period. The following questionnaires were used for data collection.

NEO-FFI Personality Inventory (NEO-FFI): This questionnaire contains 60 questions and measures five major personality dimensions including: neuroticism (vs. emotional stability), extraversion (vs. introversion). ), Openness to experience (vs. disclosure), agreeableness (vs. militancy), and conscientiousness (vs. irresponsibility). In this questionnaire, participants rated each question on a 5-point Likert scale ( $0=$ strongly disagree, $4=$ strongly agree). Scale scores are obtained by summing up to 12 items per dimension, followed by the scoring of some items in accordance with the instructions(Costa Jr \& McCrae, 2008). Murray et al. (2009), reported Cronbach's alpha values for neuroticism, 0.83 , for extraversion, 0.58 , for experience openness, 0.35 , for agreeableness, 0.55 , and for conscientiousness 0.81 . Also, the test-retest coefficients of the questionnaire were 0.80 for neuroticism, 0.82 for extraversion, 0.61 for openness to experience, 0.70 for agreeableness, and 0.76 for conscientiousness, respectively.

Parent-Child Relationship Questionnaire (PCRS): This questionnaire was used to measure parent-child relationship. The questionnaire consists of 48 questions (24 questions about father parenting and 24 questions about mother parenting) that have two forms, one for assessing child-mother relationship and one for assessing child-father relationship. Both forms of the scale are the same except that the word "father" and "mother" is changed. However, different factors have been highlighted in parent-related forms. These factors for the father questionnaire are: positive affect, parenting education, communication or dialogue, and anger; and for the mother questionnaire are: Positive affect, role annoyance / confusion, replication, communication, or dialogue. The total score is the sum of the averages of the subscales. Parent-child interaction scale has a good internal consistency with alpha coefficient of 0.89 to 0.94 for father subscales and alpha coefficient of 0.61 to 0.94 for mother subscales and overall alpha of 0.96 . Validity of the parent-child interaction scale with good 
predictive validity has been reported at a good level and significantly differentiates children of divorced and integrated families. The components of father and mother versions, are: positive emotions with the father, conflict with the father, relationships with the father, anger at the father, positive feelings with the mother, hatred / loss of role with the mother, identification with the mother and communication with the mother, respectively. Questionnaire scoring is a 7-point Likert scale. Items 9, 13, and 14 are reversed, and then the scores of items are summed and divided by the number of items per factor (the mean of each subscale). The total score is the sum of the mean subscales. The analysis is based on the score of the questionnaire. This method summarizes the results obtained from the analysis of the scores and then judges the following: The score is 24 to 48 , the parent-child relationship being poor. The score between 48 and 96 is the average parent-child relationship. A score above 96 indicates a strong parent-child relationship.

The following ethical considerations were considered in the present study:

1. Providing written consent from students and parents participating in the research;

2. Ensuring that participants keep their information confidential;

3. Participants were allowed to withdraw from the study whenever they did not wish to continue collaborating with the researcher.

To assess the relationship between personality traits of three single-child, two-child and multi-child groups with the parent-child relationship (father-child and mother-child relationship) based on the information obtained through questionnaires, the analysis Regression was used. SPSS-24 software was used for data analysis.

\section{Results}

Descriptive data for participants' in five personality dimensions, and parent-child relationship, along with mean and standard deviation, are presented in Table 1.

Table 1. A description of the participants' scores of research variables in three groups (single- child, two-child, and multiple-child groups)

\begin{tabular}{|c|c|c|c|c|c|c|c|}
\hline \multirow{2}{*}{ Variables } & \multirow{2}{*}{ Gender } & \multicolumn{2}{|c|}{ Single-child } & \multicolumn{2}{|c|}{ Two-child } & \multicolumn{2}{c|}{ Multiple-child } \\
\cline { 3 - 7 } & & Mean & SD & Mean & SD & Mean & SD \\
\hline \multirow{2}{*}{ Neuroticism } & Male & 26.09 & 7.13 & 23.72 & 7.45 & 29.41 & 9.10 \\
\cline { 2 - 7 } & Female & 25.76 & 7.34 & 24.19 & 7.40 & 27.81 & 9.70 \\
\hline \multirow{2}{*}{ Extraversion } & Male & 31.04 & 5.42 & 29.44 & 5.59 & 26.39 & 7.10 \\
\cline { 2 - 7 } & Female & 31.22 & 5.54 & 28.54 & 5.57 & 27.71 & 7.37 \\
\hline \multirow{2}{*}{ Openness } & Male & 25.56 & 5.56 & 25.26 & 3.81 & 26.13 & 4.77 \\
\cline { 2 - 8 } & Female & 25.54 & 5.21 & 25.80 & 4 & 25.53 & 4.78 \\
\hline \multirow{2}{*}{ Agreeability } & Male & 29.41 & 5.25 & 27.65 & 4.90 & 27.22 & 6.41 \\
\cline { 2 - 7 } & Female & 29.46 & 5.48 & 27.44 & 4.88 & 28.37 & 5.98 \\
\hline \multirow{2}{*}{ Fathercientiousness } & Male & 35.07 & 5.07 & 34.50 & 6.30 & 23.19 & 8.27 \\
\cline { 2 - 7 } & Female & 34.93 & 4.83 & 34.19 & 7 & 34.31 & 7.65 \\
\hline \multirow{2}{*}{ Mother-child relationship } & Male & 18.62 & 5.03 & 19.53 & 5.03 & 17.42 & 5.25 \\
\cline { 2 - 7 } & Female & 18.44 & 5.25 & 19.81 & 5.32 & 18.80 & 5.54 \\
\hline
\end{tabular}


Table 2 presents the regression analysis of the personality traits as predictor variables in explaining the mother-child relationship and the father-child relationship in single-child, two-child, and multiple-child families.

Table 2. Results of regression test for association between personality traits and parent-child relationship

\begin{tabular}{|c|c|c|c|c|c|c|c|}
\hline \multirow{3}{*}{ Predictors } & \multirow{3}{*}{$\mathrm{N}$ of Children } & \multicolumn{6}{|c|}{ Criterion } \\
\hline & & \multicolumn{3}{|c|}{ Father-child relationship } & \multicolumn{3}{|c|}{ Mother-child relationship } \\
\hline & & $\beta$ & $\mathrm{t}$ & $\mathrm{p}$ & $\beta$ & $\mathrm{t}$ & $\mathrm{p}$ \\
\hline \multirow{3}{*}{ Neuroticism } & Single-child & -0.232 & -3.37 & 0.001 & -0.25 & -3.99 & 0.001 \\
\hline & Two-child & -0.235 & -3.66 & 0.001 & -0.38 & 5.29 & 0.001 \\
\hline & Multiple-child & -0.29 & -4.09 & 0.001 & -0.39 & 5.32 & 0.001 \\
\hline \multirow{3}{*}{ Extraversion } & Single-child & 0.32 & 5.49 & 0.001 & -0.17 & -1.96 & 0.046 \\
\hline & Two-child & 0.23 & 5.28 & 0.001 & 0.22 & 9.51 & 0.001 \\
\hline & Multiple-child & 0.24 & 3.87 & 0.001 & 0.17 & 3.17 & 0.005 \\
\hline \multirow{3}{*}{ Openness } & Single-child & 0.18 & 2.38 & 0.03 & 0.10 & 2.24 & 0.026 \\
\hline & Two-child & 0.15 & 2.17 & 0.04 & 0.11 & 2.19 & 0.023 \\
\hline & Multiple-child & 0.32 & 7.11 & 0.001 & 0.13 & 2.14 & 0.021 \\
\hline \multirow{3}{*}{ Agreeability } & Single-child & 0.20 & 2.30 & 0.017 & 0.12 & 1.97 & 0.048 \\
\hline & Two-child & 0.18 & 2.22 & 0.036 & 0.18 & 3.23 & 0.004 \\
\hline & Multiple-child & 0.14 & 2.18 & 0.04 & 0.20 & 6.20 & 0.001 \\
\hline \multirow{3}{*}{ Conscientiousness } & Single-child & 0.34 & 8.12 & 0.001 & -0.14 & -2.38 & 0.017 \\
\hline & Two-child & 0.20 & 2.71 & 0.019 & 0.056 & 0.008 & 0.61 \\
\hline & Multiple-child & 0.15 & 2.14 & 0.037 & 0.033 & 0.012 & 0.55 \\
\hline \multicolumn{8}{|c|}{ Regeression overall result } \\
\hline \multirow{3}{*}{$\mathrm{R}^{2}$} & Single-child & \multicolumn{3}{|c|}{0.495} & \multicolumn{3}{|c|}{0.208} \\
\hline & Two-child & \multicolumn{3}{|c|}{$=0.254$} & \multicolumn{3}{|c|}{0.369} \\
\hline & Multiple-child & \multicolumn{3}{|c|}{$=0.263$} & \multicolumn{3}{|c|}{$=0.327$} \\
\hline
\end{tabular}

$* *$ Sig. $\mathrm{p}<0.01 \& * \mathrm{p}<0.05$

According to Table 2, taking into account the $\mathrm{R}^{2}$ values and their corresponding significant levels, personality traits significantly correlated with father relationships in students $12-15$ Year-old and it explains the $49.5 \%$ of variance. Also, personality traits in single-child families significantly explain the total relationship with the mother, and it explains the $20.8 \%$ of variance.

The personality traits in the two children families significantly explain the total relationship with the father and it explains the $25.4 \%$ of variance and personality traits in two-child families significantly explain the total 
relationship with the mother, and it explains the $36.9 \%$ of variance.

Correspondingly, according to table 2 , the personality traits in the multiple children families significantly explain the total relationship with the father and it explains the $26.3 \%$ of variance and personality traits in multiple-child families significantly explain the total relationship with the mother, and it explains the $32.7 \%$ of variance.

\section{Discussion}

The purpose of this study was to investigate the relationship between personality characteristics of students of single-parent, two-parent and multi-child families with their parent-child relationship. The results of data analysis showed that in single-parent families, there is a greater relationship between personality traits and father-child relationship than other families, and in the case of mother-child relationship, there is a stronger relationship with personality traits in multiple children families. There has been a great deal of agreement about the results of the research with the research by Heratian et al. (2015). They argue that parents with single child have higher scores in early maladaptation because the presence of children in the family creates some kind of psychological security and confidence in them, the environment and, of course, the future. In addition, it increases parental self-esteem.

The results also show that there is a significant relationship between parent-child relationship and personality dimensions and there is no significant relationship in the case of conscientiousness in the two-parent and multi-child families. Individuals with a high score in neuroticism usually have intrinsic traits and a tendency to socialize outside the home, so they will have a better relationship with their parents. As well as, individuals with a high score in open to the experience are usually creative, innovative and receptive, and this high acceptance makes them have more with their parents than peers. But in case of conscientiousness, and considering this fact that these students also have a significant relationship with their mother, it can be said students with a high score in conscientiousness usually hold their own in relation to home and family affairs. They are responsible for themselves and have a stronger relationship with their families, especially the mother, who is more involved with her children. Research shows that parents' use of proper parenting styles has a significant impact on adolescent maladaptation(Jaafari, 2017). Children living in a turbulent family often face aggression and other abusive behaviors when faced with problems, and as a result, their social skills are reduced. Children's behavioral disorders, which usually appear as maladaptive, abnormal, unethical, and anti-social behaviors of children, are caused by parenting behaviors.

Demographic changes in Iran also require specific policies regarding parenting to allow better management of families. In line with the results of this study, addressing issues that improve personality, mental health, and relationships is considered a vital need of a society.

Parents training about proper and logical relationship with their children are a practical application of research, as it is necessary to try to inform more parents about the effects of parent-child relationship on adolescent's psychological and behavioral characteristics.

The possibility of cultural differences as well as age differences between children and parents are limitations to generalization of results. Furthermore, the lack of objective measurement of indicators (personality traits and parent-child relationship) and lack of access to other influencing variables were important limitations of the study. 


\section{Acknowledgment}

We would like to take this opportunity to thank all the students, parents and school principals in Sari who have contributed to this research.

\section{Declaration of Conflicting Interests}

The author(s) declared no potential conflicts of interest with respect to the research, authorship, and/or publication of this article.

Funding: The author(s) received no financial support for the research, authorship, and/or publication of this article.

\section{References}

Allen, Bem P. (2015). Personality theories: Development, growth, and diversity: Psychology Press.

Avia, MD, Sanz, J, Sánchez-Bernardos, ML, Martínez-Arias, MR, Silva, F, \& Graña, JL. (1995). The five-factor model-II. Relations of the NEO-PI with other personality variables. Personality and Individual Differences, 19(1), 81-97.

Basu, Alaka Malwade, \& Desai, Sonalde. (2010). Middle class dreams: India's one child families. Paper presented at the Population Association of America Annual Conference, Dallas, Texas: April.

Carnes-Holt, Kara. (2012). Child-parent relationship therapy for adoptive families. The Family Journal, 20(4), 419-426.

Cervone, Daniel, \& Pervin, Lawrence A. (2015). Personality, binder ready version: theory and research: John Wiley \& Sons.

Chan-Ob, Tinnakorn, Boonyanaruthee, Vudhichai, Pinyopornpanich, Manee, Intaprasert, Suthi, \& Kuntawongse, Nahathai. (2002). The birth order and personalities of medical students. Journal of the Medical Association of Thailand= Chotmaihet thangphaet, 85(1), 97-101.

Costa Jr, Paul T, \& McCrae, Robert R. (2008). The Revised NEO Personality Inventory (NEO-PI-R): Sage Publications, Inc.

Fadaei, Elham, Kanani, Kobra, Molavi, Hossein, \& Nouri, Abulghassem. (2009). A comparison of neuroticism of Abusive and Non-abusive Husbands and Their characteristics as perceived by their wives in Isfahan, 2007. Knowledge \& Research in Applied Psychology, 67-78.

Goel, Manisha, \& Aggarwal, Preeti. (2012). A comparative study of self confidence of single child and child with sibling. International journal of research in social sciences, 2(3), 89-98.

Ha, Tshui Sun, \& Tam, Cai Lian. (2011). A study of birth order, academic performance, and personality. Paper presented at the International Conference on Social Science and Humanity, IPEDR.

Helle, Ashley C, Trull, Timothy J, Widiger, Thomas A, \& Mullins-Sweatt, Stephanie N. (2017). Utilizing interview and self-report assessment of the Five-Factor Model to examine convergence with the alternative model for personality disorders. Personality Disorders: Theory, Research, and Treatment, 8(3), 247.

Heratian, Abbas Ali., Satourian, Seyed Abbas., Zarei, Mohammad., Janbuzargi, Masoud., \& Agaharis, Mojgan. (2015). Investigation of differences in marital conflict, irrational beliefs, early maladaptive psychoses, and religious commitment of parents with one and more children. Journal of Psychology and Religion, 31(93-112 [In Persian]). 
Jaafari, Shahla. (2017). Comparison of the personality profile of adolescents in single children and adolescents in multiparous families. (M.Sc), Islamic Azad University, Marvdasht Branch, Iran [In Persian].

Liu, Chenying, Munakata, Tsunetsugu, \& Onuoha, Francis N. (2005). Mental health condition of the only-child: a study of urban and rural high school students in China. Adolescence, 40(160).

Morss, John R. (1990). The biologising of childhood: Developmental psychology and the Darwinian myth: Taylor \& Francis.

Murray, Greg, Judd, Fiona, Jackson, Henry, Fraser, Caitlin, Komiti, Angela, Pattison, Pip, \& Robins, Garry. (2009). Personality for free: Psychometric properties of a public domain Australian measure of the five-factor model. Australian Journal of Psychology, 61(3), 167-174.

Norman, Warren T. (1963). Toward an adequate taxonomy of personality attributes: Replicated factor structure in peer nomination personality ratings. The Journal of Abnormal and Social Psychology, 66(6), 574.

Pervin, Lawrence A. (1970). Personality: Theory, assessment, and research. Oxford, England: John Wiley \& Sons.

Philip, Smitha. (2015). Personality development and parental support a comparative analysis on only children and children with siblings in bangalore life. Sardar Patel University, India.

Polit, Denise F, \& Falbo, Toni. (1987). Only children and personality development: A quantitative review. Journal of Marriage and the Family, 49(2), 309-325.

Popov, Leonid M, \& Ilesanmi, Ruth A. (2015). Parent-child relationship: Peculiarities and outcome. Rev. Eur. Stud., 7, 253.

Riggio, Heidi R. (1999). Personality and social skill differences between adults with and without siblings. The Journal of Psychology, 133(5), 514-522.

Schaffer, H Rudolph. (2006). Key concepts in developmental psychology: Sage.

Schultz, Duane P, \& Schultz, Sydney Ellen. (2016). Theories of personality: Cengage Learning.

Shakerinia, Iraj, \& Asghari, Farhad. (2016). The Associations between Parent-Child Relationship and Aggressive Behavior among Students. Quarterly Journal of Child Mental Health, 2(4), 21-34.

Stronge, Samantha, Shaver, John H, Bulbulia, Joseph, \& Sibley, Chris G. (2019). Only children in the 21st century: Personality differences between adults with and without siblings are very, very small. Journal of Research in Personality, 83, 103868.

Werneck, Harald, Eder, Maximilian Oscar, Yanagida, Takuya, \& Rollett, Brigitte. (2014). Predicting adolescents' parent-child relationship quality from parental personality, marital conflict and adolescents' personality. European Journal of Developmental Psychology, 11(2), 159-176.

Yaacob, Nik Rosila Nik, \& Siew, Huong Sin. (2010). Mother working status and physical aggressive behaviour among children in Malaysia. Procedia-Social and Behavioral Sciences, 5, 1061-1066. 